\title{
Validation of phytochemicals, antioxidant activity and characterization of green synthesized iron nanoparticles: A comparison
}

\author{
Tamanna Kumari \\ Department of Zoology, M. D. University, Rohtak (Haryana), India \\ Vineeta Shukla* \\ Department of Zoology, M. D. University, Rohtak (Haryana), India \\ *Corresponding author: E mail: prof.vineetashukla@gmail.com
}

\section{Article Info}

https://doi.org/10.31018/

jans.v13i3.2894

Received: August 6, 2021

Revised: September 8, 2021

Accepted: September 12, 2021

\section{How to Cite}

Kumari, T. and Shukla, V. (2021). Validation of phytochemicals, antioxidant activity and characterization of green synthesized iron nanoparticles: A comparison. Journal of Applied and Natural Science, 13(3), 1102 - 1110. https://doi.org/10.31018/ jans.v13i3.2894

\begin{abstract}
Research on green synthesis in nanotechnology is a forthcoming field in the modern material science area. Potentiality utilization of metal and semiconductor nanoparticles is an area of vast research that makes them a suitable candidate for expanding highly innovative technologies. This study evaluated the effect of the drying method for leaves of the plant, Azadirachta indica on phytochemicals characteristics of extracts, bioactivity attributes and characteristics of nanoparticles (NPs) accommodating varied keen compounds. Synthesis of iron ( $\mathrm{Fe}$ ) nanoparticles was done using the green bottom-up method, in which aqueous extract of $A$. indica leaves acted as an extremely promising reducing and stabilizing agent. Various characterization techniques such as EDX (Energy Dispersive X-Ray Analysis), FESEM (Field Emission Scanning Electron Microscopy), FT-IR (Fourier Transform Infrared Spectroscopy), UV-VIS spectroscopy, XRD (X-Ray Diffraction) crystallography, Zeta potential and sizer confirmed the fabrication of iron nanoparticles. The quantification results established that oven-dried leaves extract had a higher total phenolic content (108.23 mg GAE/g) and free radical scavenging capacity $(250.165 \mathrm{mg} \mathrm{GAE} / \mathrm{g})$ than air-dried leaves extract. Characterization results endorsed that air-dried leaves extract acted as an advanced reducing agent that can swap the time consuming and perilous chemical synthesis of nanoparticles for a scalable formulation. The clear, intense XRD peaks revealed the crystalline nature of NPs, EDX results confirmed the purity of samples and finally, FT-IR analysis exhibited the presence of phytomolecules along with Fe NPs in final product obtained.
\end{abstract}

Keywords: Green synthesis, Iron nanoparticles, Phytochemicals, Polyphenols, Total antioxidant activity

\section{INTRODUCTION}

Nanotechnology is a promising revolution of the $21^{\text {st }}$ century world. The term nanotechnology was given by scientist Norio Taniguchi, Tokyo University, in 1974, while Feynman R. P. (Nobel laureate) conferred nanotechnology amid his address in 1959 "There's plenty of room at the bottom" (Bhateria et al., 2021). According to IUPAC defined nanoparticles in 1997, the particles whose size varies from $1 \times 10^{-7}$ to $1 \times 10^{-9}$ of any shape. Various natural processes lead to nanoparticles production like cosmological, geological, metrological etc. Nano objects have innovative attributes and behaviour that contrast remarkably from corresponding bulk counterparts reason being their large surface area to volume ratio. Nanotechnology involves the employment of nanomaterials that are natural, incidental, or manufactured particles in unbound, and/or aggregate, and/or agglomerated having at least one external dimension of length in between 1-100 nm (Hoyt and Mason, 2004; European commission, 2011; Fuster et al., 2021).

Nanotechnology shaves all regimen being interdisciplinary in nature by abstracting opportunities in physics, chemistry, biology, material science etc. Researcher constant efforts was to develop a more efficient, facile, cost-friendly, sustainable, environmentally safe, singlestep process alternative for large scale production of nanoparticles as a symbolic presentation of the progress of mankind. And the search ends at the biological entities like microorganisms and plants. Wang (2010) introduced the term green chemistry amid a project floated by EPA (Environmental Protection Agency) by United States (US). The aim of the project was to enforce imperishable advancement in synthetic automation (Wardencki et al., 2005). The prolonged and high exposure to solvents used in chemical synthesis cause 
occupational disease like carcinogenicity. The main aim of green chemistry is the replacement of the perilous solvent by the greener ones and the synthetic method that are more reproducible, scalable. The green technology results in improved morphology, prevention of agglomeration and aggregation of nanoparticles (Ajiboye et al., 2021).

The physical attributes of Fe NPs associated with core matter like magnetism and plasmon coupling broaden the application fields (Mulens-Arias et al., 2021). Recently, Fe NPs are employed in important therapeutic applications, including bio-separation, detection, correct and localized delivery of cargos, i.e. biological entities like protein, RNA, enzyme, drugs etc. due to their magnetic attributes. Their adaptability to modified surface functionalization in external magnetic fields broadens their clinic potentiality (Wei and Wang, 2008). Magnetic Fe NPs have a small size and large surface, so they carry high energies on their surface. Therefore, to minimize it, they favour aggregate. Besides, nude magnetite Fe NPs get oxidized in air quickly due to their high reactivity, which results in losing magnetism as well as dispersibility.

Cost of micro-organism isolation, culture media and risk of contamination can be cut off using less managed, perennial, sustainable, easily available, wide distribution, eco-friendly plant parts extract. Plants serve multiple purposes in human civilization since the golden ages, recent being the cost-effectivity in synthesizing nanoparticles over micro-organisms. Azadirachta indica is a part of the Meliaceae family and a native of tropical regions. Neem tree products are called a rural pharmacy in India as they are employed for their medicinal attributes since the golden ages. Neem products exhibit oviposition, deterrent, ovicidal, insect growth inhibitor, antifeedant, repellent, anthelmintic, antidiabetic, antifungal, antibacterial, antiviral, contraceptive, and sedative (Dodia et al., 2008; Pattnayak and Nayak, 2013; Ahmad et al., 2019). This is why neem is used in Veterinary, Ayurveda and Unani herbal curing techniques during the prehistoric period and found a potent use in the pharmaceutical industry nowadays. Neem oil is the key product that is obtained from various parts in varied concentrations like fruits $(4.6 \%)$, seed $(20 \%)$, kernel (18.5-52\%) (Kumar and Parmar, 1998; Deka et al., 2021). Neem oil's prime constituents are limonoids from triterpenes groups from a diverse pool of about 300 biologically active compounds (Nicoletti et al., 2012; Chandramohan et al., 2016; Gupta et al., 2017; Ferreira and Alves, 2021). Azadirachtin is the first ingredient isolated from neem seeds by Butterworth and Morgan in 1968 that showed tremendous effectivity against pests. Its chemical structure is like the ecdysones hormone of insects that helps in metamorphosis. So, it acts as a potent growth regulator, causes sterility in female insects and feeding deterrents, so it turns out to be a broad spectrum.

Azadirachta indica plant parts like seeds, leaves, bark etc., are employed for green synthesis. The main agent in plant part mediated nanoparticles (NPs) synthesis are phyto-molecules like terpenoids, alkaloids, flavonoids etc. Interestingly most phytochemicals are watersoluble that paved the way for cheap, nonhazardous solvents. Biodegradability of these phytochemicals as the capping agents prevent site contamination and does not affect the adsorption of NPs on active site surface (Badmus et al., 2018). Quick degradation of active ingredients makes user and non-target organisms safe, renewable and hinders resistance and resurgence. Flavonoids have low reduction potential, making them thermodynamically feasible to reduce metal ions by changing their enol-form to keto-form. The food industry is attracted towards the use of plants as an antioxidant replacing the synthetic ones due to their nutraceutical role against various lifestyle-related disease like diabetes, hyperlipidemia, digestive problems, cephalgia, renal malfunction and others (Nahak and Sahu, 2011; Dhama et al., 2021). The main aim of the present research work was to evaluate the effect of the drying method on phytochemical analysis, total phenolic content, antioxidant capacity and characteristics of Fe NPs.

\section{MATERIALS AND METHODS}

\section{Chemicals and reagents}

$\mathrm{FeCl}_{3} \cdot 6 \mathrm{H}_{2} \mathrm{O}, \mathrm{HCl}$, picric acid, $\mathrm{NaOH}$, isopropyl alcohol, ammonium hydroxide, chloroform, sulfuric acid, acetic acid, ethanol, sodium picrate of analytical grade and high purity were used throughout the study. Double distilled water was used during the complete study.

\section{Collecting $A$. indica (neem) leaves}

Fresh and healthy leaves of neem were collected from the herbal garden, Maharshi Dayanand University, Rohtak, Haryana, India. The collected samples were cleaned thoroughly manifold under running tap water and air and oven-dried separately. The air-dried and oven-dried leaves were grounded to a fine powder separately with an electric grinder.

\section{Plant extract preparation}

$5 \mathrm{gm}$ of air-dried and oven-dried leaves powder were boiled at $80^{\circ} \mathrm{C}$ (for 1 hour) separately in $100 \mathrm{ml}$ distilled water and then the solution was filtered using What's man filter paper. The obtained leaves extract or filtrates using air-dried and oven-dried leaves were abbreviated as sample $A$ and sample $B$, respectively and stocked at $4{ }^{\circ} \mathrm{C}$ for the further experiment, i.e. for preparation of nanoparticles. 


\section{Green synthesis of iron nanoparticles}

$0.001 \mathrm{M}$ solution of Ferric chloride hexahydrate was prepared using distilled water. 1:1 ratio of ferric precursor was blended with sample $A$ and sample $B$ separately with constant stirring at $50-60^{\circ} \mathrm{C}$ for 30 minutes (Pattanayak \& Nayak, 2013; Wang et al., 2014a) and then centrifuged at $10000 \mathrm{rpm}$ for 40 minutes. The prepared NPs (abbreviated as sample 1 and sample 2, respectively) were oven-dried for 24 hours, separately and used to characterize nanoparticles.

Phytoconstituents analysis of both plant extracts (sample A and B) and nanoparticles (sample 1 and 2)

A) Detection of alkaloids: Both extracts and NPs were solvated with $5 \% \mathrm{HCl}$, and filtered, an aliquot was employed for further experiment. The aliquots were treated with a few $\mathrm{ml}$ of Hagner's reagent, which gave yellow precipitate and confirmed the presence of alkaloids.

B) Testing for flavonoids ( $\mathrm{NaOH}$ test): $10 \% \mathrm{NaOH}(3$ drops) were mixed to extracts and NPs that were diluted with isopropyl alcohol independently. The existence of xanthones and/or flavones, flavonols, chalcones and anthocyanins was marked by yellow-red, coffeeorange, purple-red or blue colour formation proportionately.

C) Detection of saponins (Foam height test): $5 \mathrm{ml}$ extracts and NPs were added to $5 \mathrm{ml} \mathrm{H}_{2} \mathrm{O}$ individually and the contents were heated, agitated actively till froth formation, and then acknowledged to set at room temperature.

D) Testing for quinones and anthraquinones (Ammonium hydroxide test): $10 \mathrm{mg}$ of plant extracts and NPs formerly solvated with isopropyl alcohol was mixed with a drop of concentrated ammonium hydroxide separately. Red colour appearance after 2 minutes marked the residency of anthraquinone.

E) Detection of cardiac glycoside (Baljet's test): Individually, 1: 1 ratio plant extracts and NPs were mixed to sodium picrate solution. The presence of carbenolide was indicated by the display of yellow to orange colour.

F) Testing for coumarins: $2 \mathrm{ml}$ extracts and NPs and $3 \mathrm{ml}$ of $10 \% \mathrm{NaOH}$ were mixed to $1 \mathrm{ml}$ of ethanolic aliquot of plant extracts and NPs separately, agitated and the appearance of yellow coloration shows positive results.

G) Detection for phlobatannins (Precipitate test): Independently $2 \mathrm{ml}$ extracts and NPs were added to $2 \mathrm{ml}$ of $1 \% \mathrm{HCl}$, and the contents were heated in the beaker. The formation of red precipitate showed positive results.

H) Detection of steroids and / or triterpenoids: a) Salkowski test: 10 drops of the extracts and NPs solv- ated with isopropyl alcohol were mixed with $2 \mathrm{ml}$ of chloroform and $1 \mathrm{ml}$ concentrated sulfuric acid, separately dropwise till double phase emergence. In the middle layer appearance of a dish of brown color was symbolic of a steroidal ring.

b) Lieberman Bouchard test: $2 \mathrm{~mL}$ of the extracts and NPs solvated with isopropyl alcohol were mixed with $1 \mathrm{~mL}$ of anhydrous acetic acid and 3 drops of concentrated sulfuric acid, separately. Blue-green colour in the middle layer was symbolic of sterols, but pink, red, magenta or violet colour marked the existence of terpenoids after 5 minutes.

I) Detection of tannins: Individually, $10 \mathrm{mg}$ of ethanolic extracts and NPs were mixed with $2 \mathrm{~mL}$ of distilled water accompanied by 4 drops of $10 \% \mathrm{w} / \mathrm{v}$ aqueous solution of ferric chloride. The development of a blue or green colour marked the residency of phenols.

\section{Determination of total phenolic content (TPC) of plant extracts}

TPC was estimated by Folin Ciocalteu's reagent method (Devatha et al., 2018). The plant extracts (sample A\&B) were added to distilled water and then $0.15 \mathrm{ml}$ of Folin Ciocalteu's reagent was added to it. After 5 minutes of incubation, $500 \mu$ l of sodium carbonate solution (20\% W/V) was added and mixed properly using a vortex shaker. The tubes were incubated for 30 minutes in the dark, and absorbance was recorded at $765 \mathrm{~nm}$. The results obtained were expressed as Gallic acid equivalents (GAE) using Gallic acid as standard.

\section{In vitro antioxidant assay}

The antioxidant capacity of plant extracts (sample $\mathrm{A} \& \mathrm{~B}$ ) was examined in acidic $\mathrm{pH}$ using phosphomolybdate as suggested by Diab et al., 2021 with slight modification. $0.1 \mathrm{ml}$ plant extract treated with phosphomolybdate reagent $(28 \mathrm{mM}$ sodium phosphate, $4 \mathrm{mM}$ ammonium molybdate. $0.6 \mathrm{M}$ sulphuric acid) was incubated for 1 hour and 30 minutes at $95^{\circ} \mathrm{C}$. Incubation was followed by cooling of samples and absorbance was measured at $695 \mathrm{~nm}$ at room temperature. Methanolic phosphomolybdate reagent acted as control solution and the readings were taken against the reference of gallic acid solution in methanol.

\section{Characterization of NPs}

Immediate confirmation of NPs formulation can be confirmed by $\mathrm{pH}$ analysis and for the present study, it was done using Esico 1010 digital electric microprocessor $\mathrm{pH}$ meter. To study size, morphology, elemental composition and charge on NPs, various characterization techniques such as XRD, FESEM, EDX and zeta potential were employed, respectively. The bioreduction of $\mathrm{Fe}^{3+}$ to $\mathrm{Fe}^{0}$ was confirmed immediately with the change in colour, $\mathrm{pH}$, and UV-Visible spectroscopy at M.D. University, Rohtak. The diffraction pattern of the 
samples was analyzed using Bruker D8 Advance Powder X-ray diffractometer from IISER, Pune. FESEMEDX analysis was done using Zeiss Ultra Plus Scanning Electron Microscope at IISER, Pune. EDX worked as a unified aspect of SEM. FESEM study was conducted to get the morphology and structure of synthesized NPs. FT-IR analysis was used to identify the functional group in a synthesized compound at M.D. University, Rohtak. FT-IR spectra were studied in the mid-infrared region of $4000-500 \mathrm{~cm}^{-1}$ with Bruker's Alpha II infrared spectrophotometer. Zeta sizer analysis was employed to detect particle size distribution by intensity, hydrodynamic diameter, charge on the surface of nanoparticles, responsible for its stability. Zeta sizer analysis was done using Malvern (Nano ZS) Zeta Sizer Dynamic Light Scattering at M.D. University, Rohtak at an incident angle of $90^{\circ}$. The zeta potential value of $>60 \mathrm{mV}$ reproduces excellent stability followed by a good of value $40-60 \mathrm{mV}$, while a value $<30 \mathrm{mV}$ illustrate agglomeration by virtue of van der Waals force of attraction.

\section{RESULTS}

\section{Phytochemical's screening}

The experimental results of phytochemical's screening showed the presence of the alkaloids, flavonoids, saponins, quinones and anthraquinones, cardiac glycoside, coumarins and tannins (Table 1 ) in both the plant extracts. But when the same tests were performed using NPs, the coumarins, quinones and anthraquinones were lacking. These secondary plant metabolites exhibited the reducing capacity, which helped to reduce the precursor $\mathrm{FeCl}_{3} \cdot 6 \mathrm{H}_{2} \mathrm{O}$ to $\mathrm{Fe}^{0}$.

\section{Total phenolic content analysis of plant extracts}

It is very tedious to identify every secondary metabolite, but a quantitative estimation of polyphenols concentrations was done. Quantification of polyphenols showed a concentration of 81.45 and $108.23 \mathrm{mg} \mathrm{GAE} / \mathrm{g}$ in airdried and oven-dried leaves, respectively, which are responsible for reducing and capping of NPs. The phenolic molecules coating NPs help in minimizing postharvest losses, fertilizers, herbicides, easy degradation and less toxic to non-target flora and fauna.

\section{Total antioxidant capacity of plant extracts}

The principle of phosphomolybdate assay is reduction Mo $(\square)$ to Mo $(\square)$ in low $\mathrm{pH}$, forming a green colour complex. The intensity of the green colour indicated the amount of antioxidants present in the solution. The leaves extracts were established to possess a significant total antioxidant capacity of oven-dried leaf extract (250.165 mgGAE/g)>air dried leaf extract (180.165 $\mathrm{mgGAE} / \mathrm{g}$ ) due to the presence of polyphenols (Table

\section{$\mathrm{pH}$ test results of Fe NPs}

The change in colour of the solution from yellow to black immediately after mixing iron precursor to plant extract indicated the formation of iron nanoparticles. 1.55 was the $\mathrm{pH}$ of the freshly prepared ferric chloride solution. The $\mathrm{pH}$ value of air-dried $(\mathrm{pH}=5.30)$ and oven -dried $(\mathrm{pH}=7.06)$ leaves extract changed to 1.64 and 1.72, respectively, after the addition of ferric chloride solution establishing the presence of Fe NPs.

\section{UV-Visible analysis of iron nanoparticles}

A continuous absorption spectrum was obtained for $\mathrm{Fe}$ NPs. The absorbance peaks were observed at 226.3 $\mathrm{nm}$ for sample 1 and $227.30 \mathrm{~nm}$ for sample 2 (Fig. 1).

\section{XRD analysis of iron nanoparticles}

The study done at $2 \theta$ of a range from $20^{\circ}$ to $70^{\circ}$ indicated that all iron and iron oxide species fall under this scanning range. It used $\mathrm{Cu}-\mathrm{K}_{\alpha}$ as anode with a scanning rate of $2 \%$ minute. XRD data of nanoparticles showed the presence of iron NPs through the peak at 2theta at 43.3 as shown in Fig. 2. Utilizing the peak broadening profile size of iron NPs was calculated using Scherrer's formula,

$$
D=0.94 \lambda / \beta \cos \theta
$$

Where $\lambda$ is the wavelength $(1.5418 \AA), \beta$ is the line broadening at half of the maximum intensity (FWHM-full width at half maximum) in radians of the respective peaks, $\theta$ is Bragg angle of diffraction and 0.94 is the value of $\mathrm{K}$, a dimensionless shape factor. The calculat-

Table 1. Phytochemical analysis of $A$. indica extracts (Sample A-Air-dried leaves, Sample-B Oven-dried leaves) and NPs (Sample 1 \& 2)

\begin{tabular}{lll}
\hline Phytochemical & Plant extracts & Nanoparticles \\
\hline Alkaloids & + & + \\
Flavonoids & + & + \\
$\begin{array}{l}\text { Saponins } \\
\text { Quinones and }\end{array}$ & + & + \\
$\begin{array}{l}\text { anthraquinones } \\
\text { Cardiac }\end{array}$ & + & - \\
glycoside & + & + \\
Coumarins & + & \\
$\begin{array}{l}\text { Phlobatannins } \\
\text { Steroids/ or }\end{array}$ & - & - \\
triterpenoids & - & - \\
Tannins & + & + \\
\hline
\end{tabular}

Table 2. TPC and TAC of plant extracts (Sample A-Airdried leaves, Sample-B Oven-dried leaves)

\begin{tabular}{lll}
\hline Samples & $\begin{array}{l}\text { Total phenolic con- } \\
\text { tent (mg GAE/g) }\end{array}$ & $\begin{array}{l}\text { Total antioxidant } \\
\text { capacity (mg GAE/g) }\end{array}$ \\
\hline Sample A & 81.45 & 180.165 \\
Sample B & 108.23 & 250.165 \\
\hline
\end{tabular}


ed size of NPs was 63.63nm (sample 1) and $10.76 \mathrm{~nm}$ (sample 2). The appearance of distinctive peaks in XRD graphs (Fig. 2) confirmed the crystalline nature of NPs.

\section{FESEM-EDX analysis of NPs}

Penetrating $X$-rays excite electrons resulting into voltage signals (Figs. 3,4). The $\mathrm{X}$-rays reflected from the surface of the compound gives peaks at $0.6,0.8,6.4$ and $7.0 \mathrm{keV}$ belonged to iron. The results indicated that NPs samples hold about $48.35 \%$ \& $51.70 \%$ of oxygen and $51.65 \%$ and $27.26 \%$ of iron, respectively, which indicated the purity of Fe NPs (Table 4). In addition to Fe and $\mathrm{O}$, sample- 2 contained $\mathrm{P}, \mathrm{S}, \mathrm{Cl}, \mathrm{K}, \mathrm{Ca}$ as $21.04 \%$ impurities. The results of FESEM given at

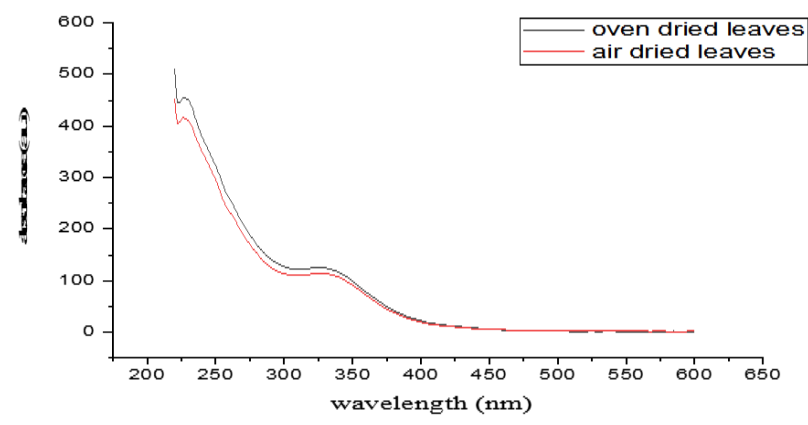

Fig. 1. UV- VIS analysis of Fe NPs (red line- sample 1; black line- sample 2)

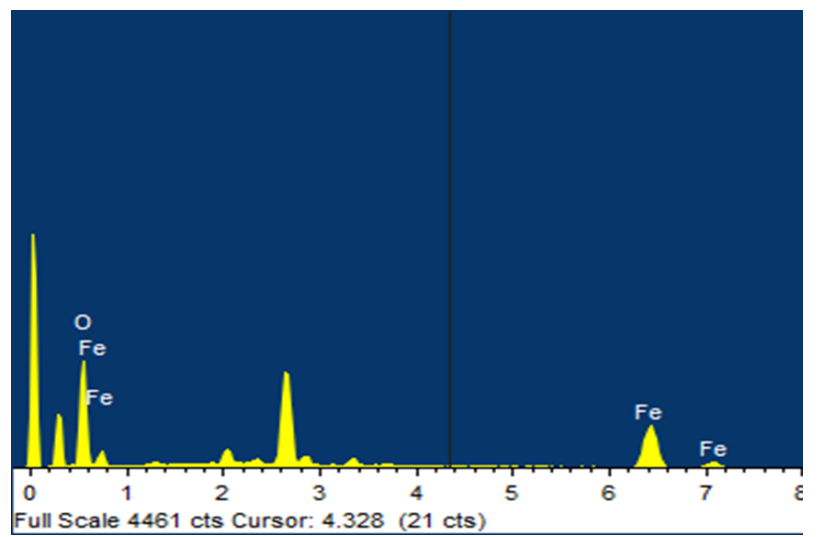

Fig. 3. EDX analysis of Fe NPs (sample 1)

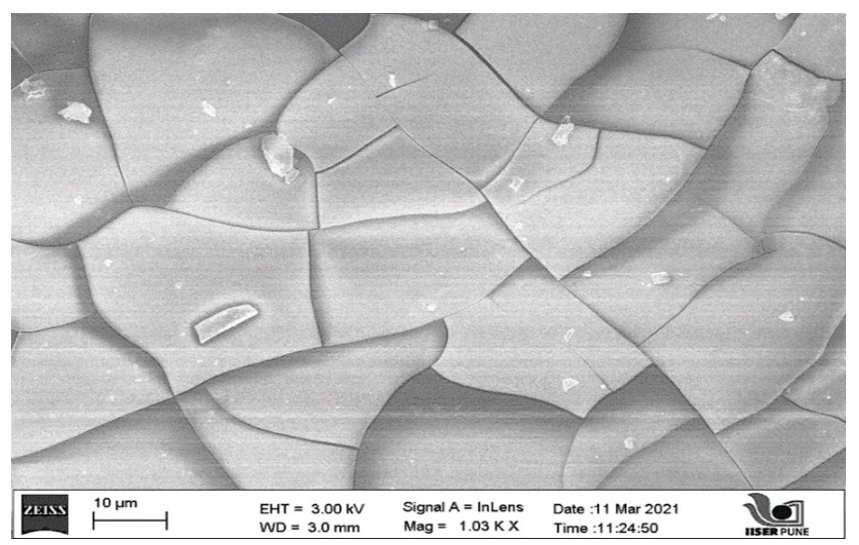

Fig. 5. FESEM images of Fe NPs (sample 1)
$10 \mu \mathrm{m}$ magnification are shown in Figs. 5,6.

\section{FT-IR analysis of iron nanoparticles}

The results confirmed that the absorbed flavonoids on the NPs surface caused steric or electrostatic hindrance that resulted in great chemical and colloidal stability (Fig. 7,8). The phytomolecules were responsible for Fe NPs formation. The presence of Fe NPs was confirmed by a strong peak at $627 \mathrm{~cm}^{-1}$ corresponding to $\mathrm{Fe}-\mathrm{O}$ in IR spectrum along with other aromatic and amines stretches (Table 5).

\section{Zeta sizer analysis}

Zeta potential of freshly prepared NPs showed a positive value of $15.5 \pm 5.99$ (Fig. 9) and 12.4 $\pm 3.62 \mathrm{mV}$ (Fig.

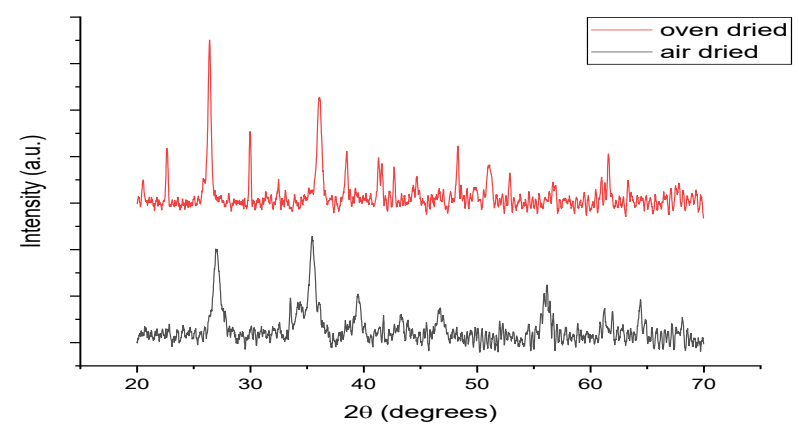

Fig. 2. XRD diffraction pattern of Fe NPs (red line-sample 2; black line- sample 1

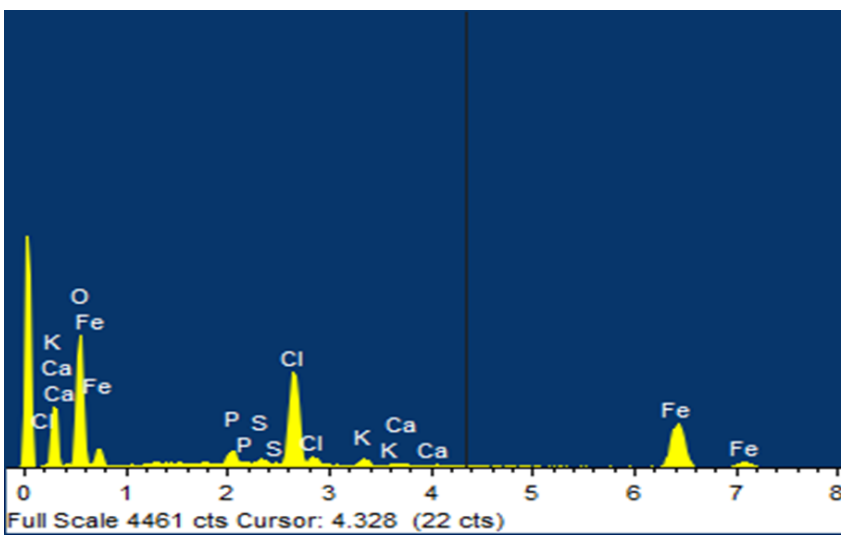

Fig. 4. EDX analysis of Fe NPs (sample 2)

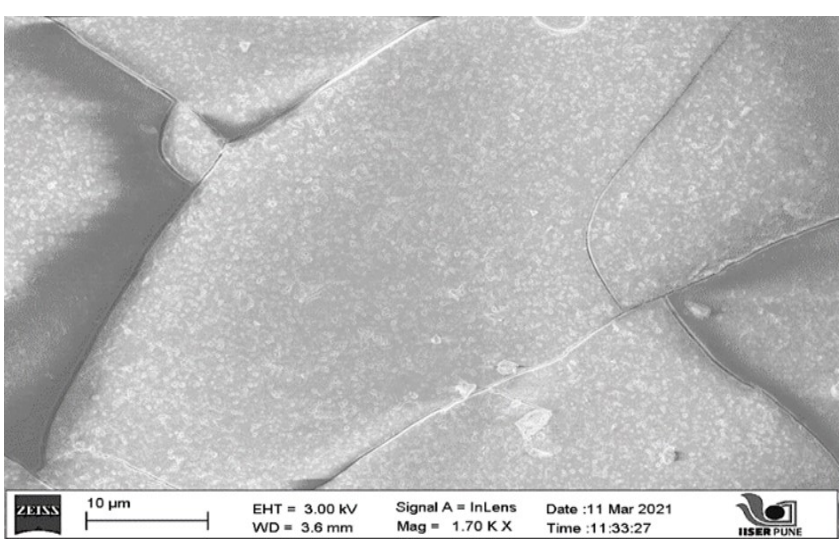

Fig. 6. FESEM images of Fe NPs (sample 2) 


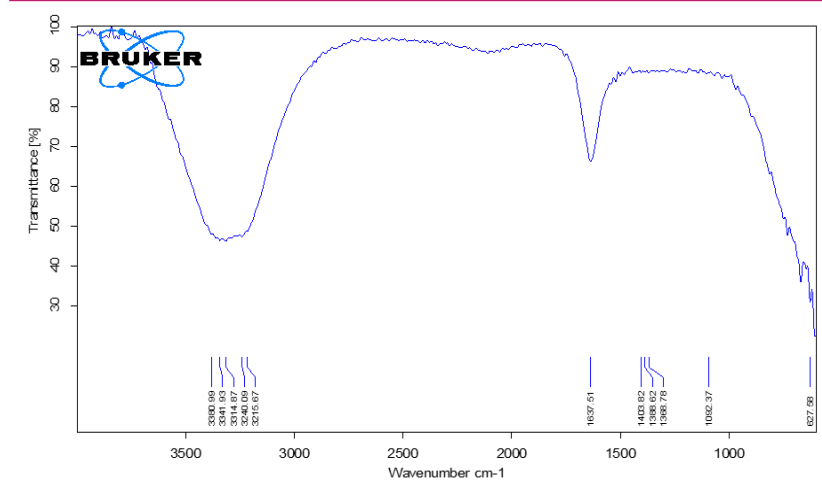

Fig. 7. FT-IR analysis of Fe NPs (sample 1)

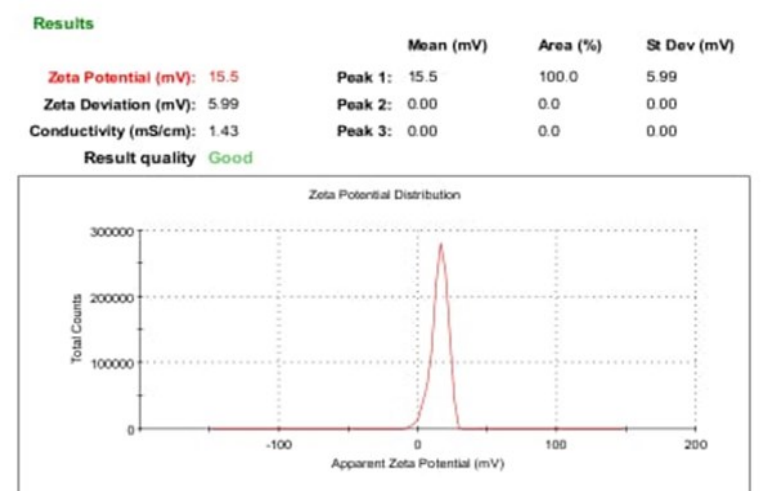

Fig. 9. The zeta potential analysis of Fe NPs (sample 1)

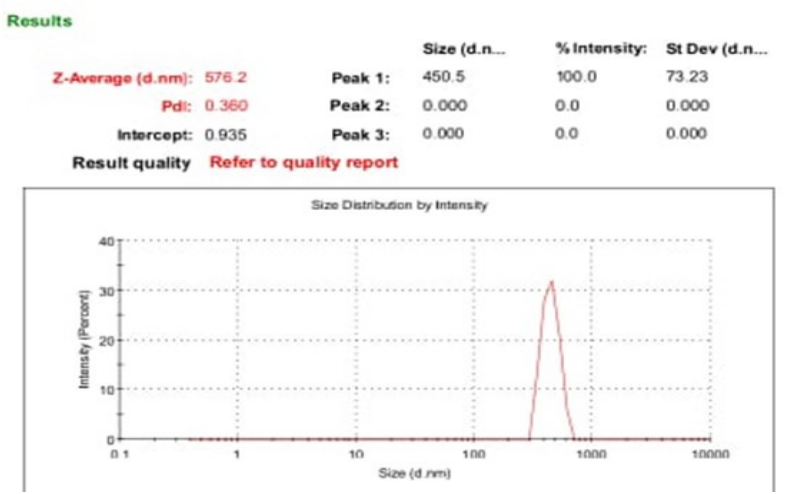

Fig. 11. Zeta sizer results of Fe NPs (sample 1)

10). The zeta sizer conferred the hydrodynamic diameter and polydispersity index of value $576.2 \pm 0.360$ (Fig. 11) and $677.9 \pm 0.499 \mathrm{~nm}$ (Fig. 12). Sonication of samples for 30 minutes followed by increased $\mathrm{pH}(>7)$ of suspension by mixing $\mathrm{NaOH}$ solution shifted the peak to -9.13 and $-11.4 \mathrm{mV}$.

\section{DISCUSSION}

Phytochemical molecules are the principles against antibiotics, insect growth inhibitors, antifeedants, repellent, anthelmintic, antidiabetic, antifungal, antibacterial, antiviral, and other medicinal values of neem. The phenolic content included secondary metabolites, pool of neem i.e., azadirachtin, azadirone, gedunin, meliacarpin, nimbin, salannin, vilasinin, gallic, tannic, and ferulic

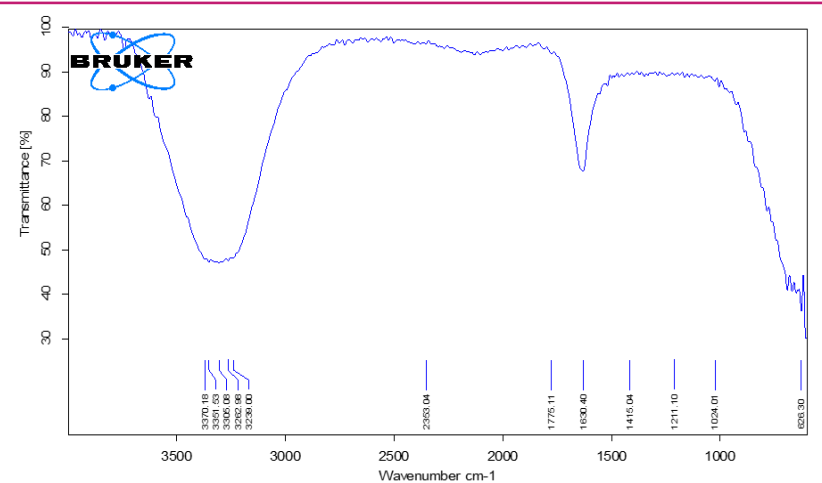

Fig. 8. FT-IR analysis of Fe NPs (sample 2)

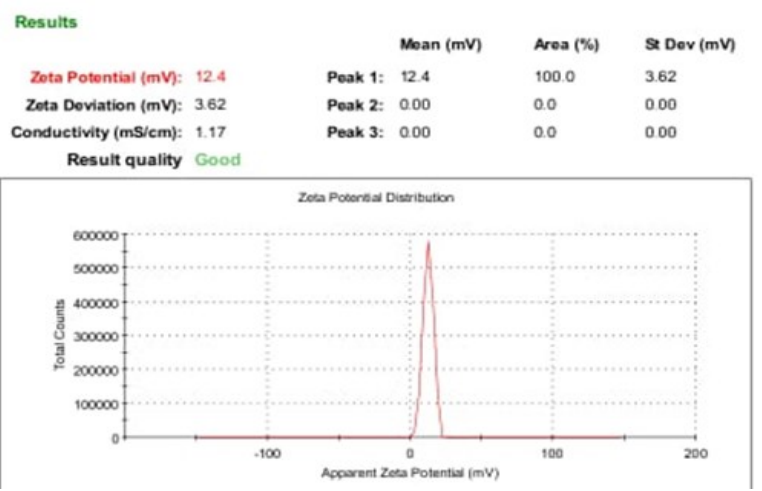

Fig. 10. The zeta potential analysis of Fe NPs (sample 2)

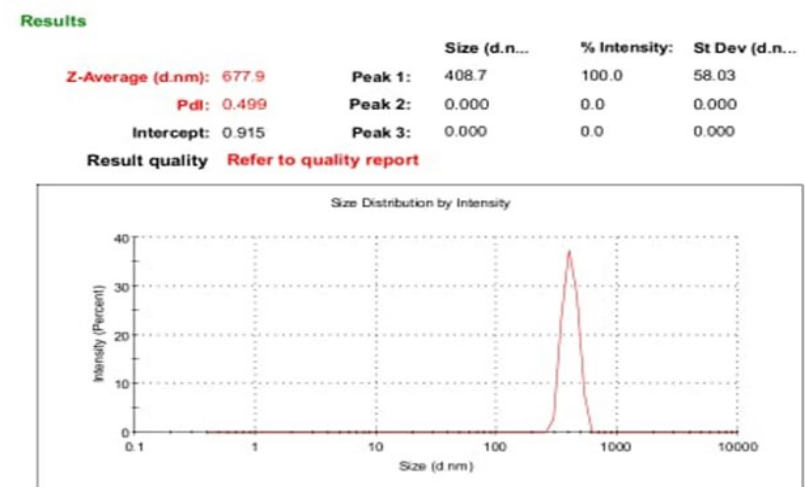

Fig. 12. Zeta sizer results of Fe NPs (sample 2)

acids, chlorogenic acid, flavonoids, tannins, alkaloids that act as pollinator attractant, antioxidant, pigmentation provider, protective agents etc. Phenolic molecules act as free radical scavengers that damage DNA, cells, cancer-causing and accelerate cell ageing. Pattanayak and Nayak (2013) synthesized Fe NPs using a low-cost reduction precursor and obtained UV-VIS spectroscopy in the range of $216-265 \mathrm{~nm}$. The results of the current study were in good agreement with them, confirming $\mathrm{Fe}$ NPs. More the intensity of XRD peaks more was the crystallite nature of NPs. Fig. 2 governs that sample 2 was more crystalline in nature than sample $1.2 \theta$ peaks (Table 3 ) confirmed the presence of secondary metabolites of the plant along with iron nanoparticles governing their stability and purity.

A comparison of the present study with the previous 
Kumari, T. and Shukla, V. / J. Appl. \& Nat. Sci. 13(3), 1102 - 1110 (2021)

\begin{tabular}{llll}
\hline \multicolumn{3}{l}{ Table 3. Diffraction pattern of green synthesized iron NPs } \\
\hline NPs & $\begin{array}{l}\text { Peak } \\
\text { (2theta) }\end{array}$ & NPs & $\begin{array}{l}\text { d spac- } \\
\text { ing (nm) }\end{array}$ \\
\hline \multirow{2}{*}{ Sample 1 } & 26.4 & $\begin{array}{l}\text { Organic mol- } \\
\text { ecules }\end{array}$ & 0.129 \\
& 43.3 & $\mathrm{Fe}_{3} \mathrm{O}_{4}, \mathrm{Fe}^{0}$ & 0.248 \\
& 51.0 & $\mathrm{FeOOH}^{2}$ & 0.20 \\
\hline \multirow{2}{*}{ Sample 2 } & 43.3 & $\mathrm{Fe}_{3} \mathrm{O}_{4}, \mathrm{Fe}^{0}$ & 0.25 \\
& 27.09 & $\begin{array}{l}\text { Organic } \\
\text { molecules }\end{array}$ & 0.092 \\
& 51.8 & FeOOH & 0.110 \\
\hline
\end{tabular}

Table 4. Elemental composition of NPs

\begin{tabular}{lll}
\hline Element & $\begin{array}{l}\text { Weight \% of } \\
\text { sample 1 (Fig. 4) }\end{array}$ & $\begin{array}{l}\text { Weight \% of sample } \\
\text { 2 (Fig. 5) }\end{array}$ \\
\hline $\mathrm{O}$ & 48.35 & 51.70 \\
$\mathrm{Fe}$ & 51.65 & 27.26 \\
$\mathrm{P}$ & - & 2.21 \\
$\mathrm{~S}$ & - & 0.70 \\
$\mathrm{Cl}$ & - & 16.33 \\
$\mathrm{~K}$ & - & 1.36 \\
$\mathrm{Ca}$ & - & 0.44 \\
Total & 100 & 100 \\
\hline
\end{tabular}

Table 5. Absorption band obtained through FT-IR spectrum

\begin{tabular}{lll}
\hline Sample & Wavelength & Functional group \\
\hline 3381 & $\begin{array}{l}\text { O-H group } \\
\text { C=C aromatic ring } \\
\text { stretching } \\
\text { C-N stretching vibration } \\
\text { of aromatic amines }\end{array}$ \\
Sample 1 & 13837 & C-O stretching vibrations \\
& 1092 & Fe-O \\
& 627 & O-H group \\
C=C aromatic ring \\
stretching \\
C-N stretching vibration \\
of aromatic amines \\
Sample 2 & 14351 & C-O stretching vibrations \\
& 1030 & Fe-O
\end{tabular}

work is shown in Table 6 . The NPs prepared are of crystallite in nature; detectable size range; produced by less stirring time, less quantity of plant extract were exploited. Also, the EDX results confirmed the purity of NPs through elemental composition and more clear peaks of X-ray reflected from NPs surface. FESEM results showed some irregularity due to agglomeration, which was due to non-uniform particle size and voids. The other absorption band of FT-IR other than Fe-O

showed that the polyphenols acted as reducing agents and capped the surface nanoparticles. The results demonstrated that $\mathrm{pH}$ played an important role as a function of zeta potential analysis. An earlier study from literature by Arakha et al. (2015), Cai et al. (2020), Al Kindi et al.( 2021), Özbaş et al. (2021) confirmed that in aqueous suspension, at higher $\mathrm{pH}$ the negative values of zeta potential change to cations at lower $\mathrm{pH}$ due to protonation of functional groups like amide, carboxyl etc. The zeta potential analysis results of the present study showed immense variation with a change in $\mathrm{pH}$. In green synthesis, the biomolecules played a significant role in the size and shape of NPs. Stability of NPs was in direct proportion to the $\mathrm{pH}$ of the suspension. The present study suggests a clean and green approach of Fe NPs synthesis in simple laboratory conditions. Due to all the earlier discussed properties of NPs, much research is being done on environmental pollution remediation on-site to reduce the toll of transportation, less chances of contamination, and non-perilous byproduct formation in nanoformulations along with increased use in agriculture. Fe NPs can have a versatile role like the plant as a growth promoter, nutrient fortification, increased and improved crop yield, promoted photosynthesis, enhanced biomass, plant protectant by mitigating heavy metal uptake etc., as iron being essential micronutrient for plants.

\section{Conclusion}

The study was emphasized to present the effect of dried leaves used as low-cost reductant on the characteristic of NPs and polyphenols concentration in extract. The NPs produced using oven-dried leaves extract were smaller in size $(10.76 \mathrm{~nm})$ than air-dried leaves extract $(63.63 \mathrm{~nm})$. Also, results produced from EDX analysis showed higher purity level for sample 1 (NPs prepared from air-dried leaf extract- $51.65 \%$ ) than sample 2 (NPs prepared from oven-dried leaf extract$27.26 \%$ ). The results are like the phenolic contents that presented the antioxidant amount of samples is in coherence with phenols. Thus, a significant concentration of antioxidants demonstrated that the leaves' cells are well protected against the ROS generated during the photorespiration process. They act as a scavenger against the free radicles produced during metabolic reactions. The present work established that the utilized leaf extracts are harmonious for environmental remediation as a substitute as the concern of toxicity and incendiary related to chemical synthesis using sodium borohydride were resolved. Also, results adequately embellished the environmentally friendly approach, which can handle biodegradable stuff effectively and having astounding relevance for the in-situ strategy for concurrent eradication. On another front, plant 
Kumari, T. and Shukla, V. / J. Appl. \& Nat. Sci. 13(3), 1102 - 1110 (2021)

Table 6. Comparison of present study with the previous work in literature

\begin{tabular}{|c|c|c|c|c|}
\hline $\begin{array}{l}\text { Iron } \\
\text { precursor }\end{array}$ & $\begin{array}{l}\text { Iron precursor: } \\
\text { plant extract } \\
\text { used }\end{array}$ & Plant extract & Results & Reference \\
\hline $\mathrm{FeCl}_{3} \cdot 6 \mathrm{H}_{2} \mathrm{O}$ & $1: 1$ & Azadirachta indica & $\begin{array}{l}\text { Crystallite nature of NPs } \\
\text { Stirring time- } 30 \text { minutes } \\
10.76 \mathrm{~nm} \& 63.63 \mathrm{~nm} \text { size } \\
\text { EDX peak at } 0.6,0.8,6.4 \text { and } 7.0 \\
\mathrm{keV} \\
\mathrm{Fe} \text { in EDX- } 51.65 \% \& 27.26 \%\end{array}$ & Current study \\
\hline $\mathrm{FeCl}_{3} \cdot 6 \mathrm{H}_{2} \mathrm{O}$ & $1: 9$ & $\begin{array}{l}\text { Cupressus } \\
\text { sempervirens }\end{array}$ & Amorphous nature of NPs & $\begin{array}{l}\text { Ebrahiminezhad et } \\
\text { al., } 2018\end{array}$ \\
\hline $\mathrm{FeSO}_{4} .7 \mathrm{H}_{2} \mathrm{O}$ & $1: 2$ & Camellia sinensis & $\begin{array}{l}\text { Stirring time- } 45 \text { minutes } \\
\text { Amorphous nature of NPs }\end{array}$ & Das and Dhar; 2020 \\
\hline $\mathrm{FeCl}_{3} \cdot 6 \mathrm{H}_{2} \mathrm{O}$ & $1: 1 ; 1: 2 ; 1: 3$ & Magnifera indica & Amorphous nature of NPs & $\begin{array}{l}\text { Desalegn et al., } \\
2019\end{array}$ \\
\hline $\mathrm{FeCl}_{3} \cdot 6 \mathrm{H}_{2} \mathrm{O}$ & $1: 2$ & Juglans regia & $\begin{array}{l}10.30 \mathrm{~nm} \text { size } \\
\text { EDX peak at } 0.7,6.4 \text { and } 7.0 \mathrm{keV}\end{array}$ & Izadiyan et al., 2020 \\
\hline $\mathrm{FeSO}_{4} .7 \mathrm{H}_{2} \mathrm{O}$ & $1: 2$ & $\begin{array}{l}\text { Magnifera indica; } \\
\text { Azadirachta indica; } \\
\text { Murraya koenigii; } \\
\text { Magnolia champaca }\end{array}$ & $\begin{array}{l}\text { Fe in EDX- 21.33\%; } 16.68 \% \text {; } \\
9.60 \% ; 12.86 \%\end{array}$ & Devatha et al., 2016 \\
\hline $\mathrm{FeSO}_{4} .7 \mathrm{H}_{2} \mathrm{O}$ & $1: 2$ & $\begin{array}{l}\text { Eucalyptus; green } \\
\text { tea }\end{array}$ & $\begin{array}{l}\text { Fe in EDX- } 16.17 \% ; 42.98 \% \\
\text { Amorphous nature of NPs }\end{array}$ & Wang et al., 2014b \\
\hline $\mathrm{FeSO}_{4} .7 \mathrm{H}_{2} \mathrm{O}$ & $1: 4$ & Centaurea cyanus & $17.5 \mathrm{~nm}$ size & $\begin{array}{l}\text { Davarnejad et al., } \\
2020\end{array}$ \\
\hline
\end{tabular}

synthesized NPs have the potential to be used as pesticides, herbicides, along with nutrient fortification.

\section{ACKNOWLEDGEMENTS}

Authors convey their heartful gratitude towards the Department of Zoology, Aryabhata Central Instrumentation Laboratory, Maharshi Dayanand University, Rohtak and Council of Scientific and Industrial Research (CSIR), Delhi, India, providing foundational and pecuniary support, respectively.

\section{Conflict of interest}

The authors declare that they have no conflict of interest.

\section{REFERENCES}

1. Ahmad, S., Maqbool, A., Srivastava, A. \& Gogoi, S. (2019). Biological detail and therapeutic effect of Azadirachta indica (neem tree) products - a review. J. Evid. Based Med. Healthc., 6(22), 1607-1612. DOI: 10.18410/ jebmh/2019/324.

2. Ajiboye, A.T., Otun, K.O., Babamale, H.F. \& Abdulra'uf, L.B. (2021). The Roles of Vegetable Fibres in Green Chemistry. In: Jawaid M., Khan A. (eds) Vegetable Fiber Composites and their Technological Applications. Composites Science and Technology. Springer, Singapore, https://doi.org/10.1007/978-981-16-1854-3_19.

3. Al Kindi, G.Y., Hassan, A.K., Yahya, D.G.H. \& Alhaidri, H.A. (2021). The nanoparticles zero-valent synthesis by black tea extract to remove rb 238 using synthetic and natural wastewater by packed bed reactor. IOP Conf.
Ser.: Earth Environ. Sci., 779, 012092. doi:10.1088/17551315/779/1/012092.

4. Arakha, M., Pal S., Samantarrai, D., Panigrahi, T.K., Mallick, B.C., Pramanik, K., Mallick, B. \& Jha, S. (2015). Antimicrobial activity of iron oxide nanoparticle upon modulation of nanoparticle-bacteria interface. Sci. Rep. 5, 14813. doi: 10.1038/srep14813.

5. Badmus, K.O., Coetsee-Hugo, E., Swart, H. \& Petrik, L. (2018). Synthesis and characterisation of stable and efficient nano zero valent iron. Environmental Science and Pollution Research, 25, 23667-23684. https://doi.org/10.1 007/s11356-018-2119-7.

6. Bhateria, R., Mona, S. \& Sharma, Y. (2021). Green Synthesized Iron Nanoparticles for Environmental Management: Minimizing Material and Energy Inputs. In: The Handbook of Environmental Chemistry. Springer, Berlin, Heidelberg, https://doi.org/10.1007/698_2021_789.

7. Cai, W., Guo, M., Weng, X., Zhang, W., Owens, G. \& Chen, Z. (2020). Modified green synthesis of $\mathrm{Fe}_{3} \mathrm{O}_{4} @ \mathrm{SiO}_{2}$ nanoparticles for $\mathrm{pH}$ responsive drug release. Materials Science \& Engineering, C 112, 110900. https://doi.org/1 0.1016/j.msec.2020.110900.

8. Chandramohan, B., Murugan, K., Panneerselvam, C., Madhiyazhagan, P., Chandirasekar, R., Dinesh, D., Kumar, P.M., Kovendan, K., Suresh, U., Subramaniam, J., Rajaganesh, R., Aziz, A.T., Syuhei, B., Alsalhi, M.S., Devanesan, S., Nicoletti, M., Wei, H. \& Benelli, G. (2016). Characterization and mosquitocidal potential of neem cake-synthesized silver nanoparticles: genotoxicity and impact on predation efficiency of mosquito natural enemies. Parasitol. Res., 115, 1015-1025. https://doi.org/1 0.1007/s00436-015-4829- 9.

9. Das, J. \& Dhar, S.S. (2020). Camellia sinensis mediated synthesis of zero valent iron nanoparticles and study of their efficacy in dye degradation and antibacterial activity. 
International Journal of Environmental Analytical Chemistry. DOI: 10.1080/03067319.2020.1828388.

10. Davarnejad, R., Azizi, A., Mohammadi M. \& Mansoori S. (2020). A green technique for synthesising iron oxide nanoparticles by extract of Centaurea cyanus plant: an optimised adsorption process for methylene blue. International Journal of Environmental Analytical Chemistry. DOI: 10.1080/03067319.2020.1756273.

11. Deka, B., Babu, A., Sarkar, S. Kanrar B. Patanjali P.K. \& Bhandari P. (2020). Role of Prosopis juliflora as a botanical synergist in enhancing the efficacy of neem kernel powder against tea red spider mites, Oligonychus coffeae (Acari: Tetranychidae). SN Appl. Sci., 2, 582. https://doi.org/10.1007/s42452-020-2354-7.

12. Desalegn, B., Megharaj, M., Chen, Z. \& Naidu R. (2019) Green synthesis of zero valent iron nanoparticle using mango peel extract and surface characterization using XPS and GC-MS. Heliyon, 5, e01750. https:// doi.org/10.1016/j.heliyon.2019.e01750.

13. Devatha, C.P., Jagadeesh, K. \& Patil, M. (2018). Effect of Green synthesized iron nanoparticles by Azardirachta Indica in different proportions on antibacterial activity. Environmental Nanotechnology, Monitoring \& Management, 9, 85-94.https://doi.org/10.1016/j.enmm.2017.1 1.0 07.

14. Devatha, C.P., Thalla, A.K. \& Katte, S.Y. (2016). Green synthesis of Iron Nanoparticles using different leaf extracts for treatment of domestic wastewater. Journal of Cleaner Production, 139, 1425-1435.

15. Dhama, K., Sharun, K., Gugjoo, M.B., Tiwari, R., Alagawany, M., Yatoo, M.I., Thakur, P., Iqbal, H.M.N., Chaicumpa, W., Michalak, I., Elnesr, S.S. \& Farag, M.R. (2021). A Comprehensive Review on Chemical Profile and Pharmacological Activities of Ocimum basilicum. Food Reviews International. DOI: 10.1080/87559129.2021.190 0230.

16. Diab, T. A., Donia, T. \& Saad-Allah, K.M. (2021). Characterization, antioxidant, and cytotoxic effects of some Egyptian wild plant extracts. Beni-Suef University Journal of Basic and Applied Sciences, 10, $13 . \mathrm{https} / / /$ doi.org/10.1186/s43088-021-00103-0.

17. Dodia, D.A., Patel, I.S. \& Patel, G.M. (2008). Botanical pesticides for pest management. ISBN: 978-81-7233-534-2.

18. Ebrahiminezhad, A., Taghizadeh, S., Ghasemi, Y. \& Berenjian, A. (2018). Green synthesized nanoclusters of ultrasmall zero valent iron nanoparticles as a novel dye removing material. Science of the Total Environment, 621, 1527 -1532. https://doi.org/10.1016/j.scitotenv.2017.10.076.

19. European Commission (2011). Commission recommendation the definition of nanomaterial (2011/696/EU). Official Journal of the European Union. L 275/38.

20. Ferreira, L.S. \& Alves, S.N. (2021). Neem (Azadirachta indica): larvicidal properties - a review. Revista Conexão Ciência, 16, 1.

21. Fuster, E., Candela, H., Estévez, J., Vilanova, E. \& Sogorb, M.A. (2021). Titanium Dioxide, but Not Zinc Oxide, Nanoparticles Cause Severe Transcriptomic Alterations in T98G Human Glioblastoma Cells. Int. J. Mol. Sci., 22(4), 2084. 10.3390/ijms22042084.

22. Gupta, S.C., Prasad, S., Tyagi, A.K., Kunnumakkara, A.B.
\& Aggarwall, B.B. (2017). Neem (Azadirachta indica): an Indian traditional panacea with modern molecular basis. Phytomedicine, 34, 14-20. https://doi.org/10.1016/j.phym ed.2017.07.001.

23. Hoyt, V. W. \& Mason, E. (2004). Nanotechnology Emerging health issues. Division of Chemical Health and Safety of the American Chemical Society, 1871-5532.

24. Izadiyan, Z., Shameli, K., Miyake, M., Hara, H., Mohamad, S.E.B., Kalantari, K., Taib, S.H.M. \& Rasouli, E. (2020). Cytotoxicity assay of plant-mediated synthesized iron oxide nanoparticles using Juglans regia green husk extract. Arabian Journal of Chemistry, 13, 2011-2023. https://doi.org/10.1016/j.arabjc.2018.02.019.

25. Kumar, J. \& Parmar, B.S. (1998). Neem oil-chemistry and bioactivity. Pesticide Research Journal, 10,14-43.

26. Mulens-Arias, V., Rojas, J.M. \& Barber, D.F. (2021). The Use of Iron Oxide Nanoparticles to Reprogram Macrophage Responses and the Immunological Tumor Microenvironment. Frontier in Immunology, 12, 693709. doi: 10.33 89/fimmu.2021.693709.

27. Nahak, G. \& Sahu, R.K. (2011). Evaluation of antioxidant activity of flower and seed oil of Azadirachta indica $A$. juss. Journal of Applied and Natural Science, 3(1), 78-81.

28. Nicoletti, M., Maccioni, O., Coccioletti, T., Mariani, S. \& Vitali, F. (2012). Neem tree (Azadirachta indica A. Juss) as source of bioinsectides. In: Perveen, F. (Ed.), Insecticides - Advances in Integrated Pest Management, InTech. https://doi.org/10.5772/ 28786.

29. Özbaş, F., Tüzün, E., Yıldız, A. \& Karakuş, S. (2021). Sonosynthesis and characterization of konjac gum/ xanthan gum supported ironoxide nanoparticles. International Journal of Biological Macromolecules, 183, 10471057. https://doi.org/10.1016/j.ijbiomac.2021.05.044.

30. Pattanayak, M. \& Nayak, P.L. (2013). Green synthesis and characterization of zero valent Iron nanoparticles from the leaf extract of Azadirachta indica (Neem). World Journal of Nano Science \& Technology, 2(1), 06-09.

31. Wang, T., Jin, X., Chen, Z., Megharaj, M. \& Naidu, R. (2014a). Green synthesis of Fe nanoparticles using eucalyptus leaf extracts for treatment of eutrophic wastewater. Science of the Total Environment, 466-467:210-213.

32. Wang, T., Jiajiang, L., Chen, Z., Megharaj, M. \& Naidu, R. (2014b). Green synthesized iron nanoparticles by green tea and eucalyptus leaves extracts used for removal of nitrate in aqueous solution. Journal of Cleaner Production, 83, 413-419.

33. Wardencki, W., Curylo, J. \& Namiesśnik, J. (2005). Green chemistry- Current and future issues. Polish Journal of Environmental Studies, 14(4), 389-395.

34. Wei, H. \& Wang, E. (2008). $\mathrm{Fe}_{3} \mathrm{O}_{4}$ Magnetic nanoparticles as peroxidase mimetics and their applications in $\mathrm{H}_{2} \mathrm{O}_{2}$ and glucose detection. Anal. Chem., 80(6), 2250-2254. https:// doi.org/10.1021/ac702203f.

35. Wang, L. (2010). Paul anastas: A pPower player in the global chemical industry. Yale Scientific Retrieved from https://www.yalescientific.org/2010/10/paul-anastas-apower-player-in-the-global-chemical-industry/ 